\title{
Vitamin D, calcium, and retinol intake, and pancreatic cancer in a population-based case-control study in the San Francisco Bay area
}

\author{
Lydia B. Zablotska $\cdot$ Zhihong Gong • \\ Furong Wang • Elizabeth A. Holly • \\ Paige M. Bracci
}

Received: 20 April 2010/ Accepted: 22 October 2010/Published online: 12 November 2010

(C) The Author(s) 2010. This article is published with open access at Springerlink.com

\begin{abstract}
Objective The aim of this study was to evaluate a complex association among intake of dietary vitamin $\mathrm{D}$, calcium, and retinol, and pancreatic cancer risk.

Methods Pancreatic cancer cases $(n=532)$ diagnosed in 1995-1999 were identified using rapid case ascertainment methods and were frequency matched to population-based controls $(n=1,701)$ in the San Francisco Bay Area. Detailed dietary data were collected during in-person interviews using a validated semi-quantitative foodfrequency questionnaire. Adjusted unconditional logistic regression was used to estimate odds ratios (ORs) and confidence intervals.

Results In men, increased pancreatic cancer risk was associated with currently recommended dietary vitamin D intake levels (highest ( $\geq 450$ IU/day) vs. lowest $(<150$ IU/ day) intake, $\mathrm{OR}=2.6$, trend- $p=0.009$ ) and total vitamin D intake from diet and supplements (for $<800 \mathrm{IU} /$ day). ORs for dietary vitamin D intake remained increased after adjustment for intake of retinol and calcium, although confidence intervals included unity. Stratified analyses showed that ORs were higher among men with lower intake of retinol and lower physical activity but there was no evidence of statistical interaction. No associations with vitamin D intake were observed among women, although ORs typically were elevated. ORs increased with increased dietary calcium intake among men (trend- $p=0.008$ ) and not women.
\end{abstract}

L. B. Zablotska $(\bowtie) \cdot$ Z. Gong $\cdot$ F. Wang ·

E. A. Holly · P. M. Bracci

Department of Epidemiology and Biostatistics, University

of California San Francisco, Box 1228, 3333 California Street,

Suite 280, San Francisco, CA 94118, USA

e-mail: lydia.zablotska@ucsf.edu
Conclusions Our results among men showing an increased risk of pancreatic cancer associated with dietary intake of vitamin $\mathrm{D}$ and of calcium require confirmation in further studies. Continued investigation is needed to clarify the complex role of vitamin D and calcium in pancreatic cancer risk and to determine their optimal intake level and preventive effects for pancreatic cancer.

Keywords Pancreatic neoplasms - Vitamin D . Vitamin A · Retinol · Calcium

\section{Introduction}

Recent medical advances have produced dramatic benefits for some cancer patients, primarily by prolonging cancerfree survival. However, 5-year survival rates for pancreatic cancer patients remain at $<5 \%$ [1]. Incidence and mortality from pancreatic cancer have not abated in the United States and continue to increase around the world, partly due to few known modifiable risk factors and non-specific symptoms that contribute to advanced-stage disease with few treatment options at diagnosis [2]. Thus, development of effective preventive strategies remains a priority.

Other than cigarette smoking, modifiable risk factors for pancreatic cancer have not been consistently identified, although obesity, heavy alcohol consumption and some dietary factors have been reported [3, 4]. Dietary factors that can be altered both by dietary changes and by use of supplements have been a target of scientific investigation but results from epidemiological studies have been inconsistent $[3,5,6]$. Vitamin $\mathrm{D}$ is of particular interest because deficiency is associated with diabetes [7,8], a suggested risk factor for pancreatic cancer. In general, vitamin D levels are influenced more by sun exposure than by diet [9], 
with fortified foods being a significant dietary source of vitamin D in the US. Sun exposure has been linked with lower cancer incidence and/or cancer mortality rates from colon, breast, prostate and pancreatic cancer in ecological studies [4, 10, 11]. In addition, epidemiological studies consistently have showed significant associations between low levels of vitamin D and increased age, obesity, and African-American ethnicity, known risk factors of pancreatic cancer [12]. Because vitamin D also has been shown to have anticarcinogenic properties in pancreatic cancer cell lines [13], a strong hypothesis emerged that high levels of vitamin $\mathrm{D}$ could be related to a reduced risk of pancreatic cancer [6].

An initial report from a Finnish cohort study in male smokers showed no association between dietary vitamin D intake and pancreatic cancer [14], whereas analysis of two large prospective cohorts in the United States showed that increased dietary vitamin D was associated with a 30-40\% reduced risk of pancreatic cancer [10]. Additional analyses of Finnish male smokers with low or moderate levels of circulating metabolite 25-hydroxyvitamin D [25(OH)D], considered a more accurate measure of total vitamin $\mathrm{D}$ levels, showed increased risk of pancreatic cancer among those with the highest $25(\mathrm{OH}) \mathrm{D}$ concentrations [15]. A similar analysis of a US population with adequate or high $25(\mathrm{OH}) \mathrm{D}$ concentrations showed statistically non-significant increased risks of a smaller magnitude [16]. A recently published pooled analysis of eight cohort studies reported a statistically significant increase in risk of pancreatic cancer associated with a high $25(\mathrm{OH}) \mathrm{D}$ serum concentration [17].

In addition to sun exposure, vitamin D levels are affected by the intake of other dietary nutrients, retinol and calcium. Retinol is a known antagonist of vitamin D absorption [18], whereas calcium requires vitamin $\mathrm{D}$ for its own intestinal absorption and metabolism. At high levels, calcium regulates the production of the active form of vitamin D [19]. Both nutrients are present in many multivitamin formulations. Thus, to adequately assess the association between vitamin $\mathrm{D}$ intake and pancreatic cancer risk, statistical analyses need to evaluate the potential confounding or effect modification related to intake of these nutrients.

To further explore the association between intake of vitamin $\mathrm{D}$ (dietary and total intake consisting of diet and supplements) and risk of pancreatic cancer, we analyzed dietary data collected using a semi-quantitative food-frequency questionnaire in our large population-based casecontrol study of pancreatic cancer in the San Francisco Bay Area. We also assessed the main effects of intake of vitamin A, retinol, and calcium (dietary and total), and because of their influence on vitamin D levels, their role as confounders or modifiers of the association between vitamin $\mathrm{D}$ and pancreatic cancer. Retinol (vitamin $\mathrm{A}$ ) is a vitamin $\mathrm{D}$ antagonist and is present in many multivitamin formulations.

\section{Materials and methods}

Study population

Details of study methods and population characteristics have been described previously [20-22]. Briefly, cases were identified with incident adenocarcinoma of the exocrine pancreas diagnosed between 1995 and 1999 using rapid case ascertainment. Eligible cases were 21-85 years of age, residents of one of the six San Francisco Bay Area counties, alive, and able to complete an in-person interview in English. Pancreatic cancer diagnoses were confirmed by the participants' physicians and by Surveillance, Epidemiology and End Results (SEER) abstracts. A total of 532 eligible patients completed the interview for a response rate of $67 \%$. Control participants were identified by random digit dial supplemented by random sampling of the Health Care Finance Administration (now Center for Medicare and Medicaid Services) lists for those $\geq 65$ years old and were frequency matched to cases by sex, 5-year age group, and county of residence. Eligibility criteria were the same as for cases with the exception of their pancreatic cancer diagnosis. A total of 1,701 eligible controls completed the interview for a response rate of $67 \%$.

\section{Data collection}

Extensive data were collected using a structured questionnaire administered by trained interviewers during inperson interviews. Detailed data collected included age, race, education, diabetes status, history of smoking, alcohol consumption, physical activity, and anthropometric measures. Dietary history including use of vitamin and mineral supplements was assessed using the 131-item semi-quantitative food-frequency questionnaire (FFQ) that has been described in detail elsewhere [23] and has been validated in a variety of populations [24-28]. Participants were asked to report their average frequency of intake of specific foods and associated portion size during 1 year before the diagnosis for cases or interview for controls. The scannable questionnaires were processed by the Department of Nutrition at the Harvard School of Public Health. Macroand micronutrient intake was computed by multiplying the frequency of each food item by the nutrient content of the standard portion size specified for each food item using Harvard University's food composition database that was updated over time with data from the US Department of Agriculture sources [29]. 
No proxy interviews were conducted. The study protocols were approved by the University of California San Francisco Committee on Human Research. Written informed consent was obtained from each participant prior to interview.

\section{Statistical methods}

Standard chi-square methods were used to test the association between categorical factors and pancreatic cancer. Pearson's correlation was used to measure a linear relationship between intakes of individual nutrients when measured on a continuous scale. Odds ratios (ORs) and 95\% confidence intervals (CIs) were computed using multivariable unconditional logistic regression to estimate the relative risk (hereafter called risk) of pancreatic cancer. Tests for linear trend of the odds ratios were conducted by modeling the median value for each category as a continuous variable in multivariable logistic regression analyses. All analyses were stratified by sex, and results are presented separately for women and men. Multivariable models included age in 5-year groups, race (white, Black/ African American, Asian/Pacific Islanders, or "other"), total energy in quartiles, education level (less than high school, high school, 1-4 years college, and graduate school), usual adult body mass index (BMI: $<25,25$ to $<30$, and $\geq 30 \mathrm{~kg} / \mathrm{m}^{2}$ ), smoking status (never smoker, former cigarette smoker who quit smoking $>15$ years ago, former cigarette smoker who quit smoking $1-15$ years ago, current cigarette smoker or smoker who quit within 1 year, and pipe and/or cigar smoker), history of diabetes, frequency of leisure time physical activity as an adult (30-min: $<1 /$ month, 1-4/month, 2-3/week, and $\geq 4 /$ week), and alcohol consumption over the three decades prior to diagnosis/interview (never drinkers, $\leq 7,8-14,15-21$, and $>21$ drinks/week). Analyses were conducted for nutrient intake from food only, hereinafter referred to as "dietary" intake, and for nutrient intake from food and from vitamin supplements referred to as "total" intake. For comparability with other studies [10], participants with intake of supplements were excluded from analyses of the effects of dietary intakes.

The residual method was used to analyze categorical nutrient intake in models adjusted for total energy intake [30]. Nutrient intake was categorized into four or five groups based on the frequency distribution in the population and on cutpoints used in previously published analyses of these nutrients. Analyses stratified by smoking coded as a dichotomous variable (non-smokers: never smokers, former cigarette smokers who quit smoking $>15$ years ago, and cigar and/or pipe smokers; smokers: cigarette smokers who quit smoking 1-15 years ago, current cigarette smokers or smokers who quit within 1 year) were conducted to assess effect modification of smoking on the association between vitamin $\mathrm{D}$ intake and pancreatic cancer. Likelihood ratio tests that compared models with and without the smoking-nutrient cross-product term were used to formally test for statistical interaction.

Statistical analyses were conducted using SAS software V9.1 (SAS Institute, Inc., Cary, NC). All statistical tests were 2 -sided and considered statistically significant when $p<0.05$.

\section{Results}

Descriptive characteristics of cases and controls are presented in Table 1. Relative to controls, a higher proportion of cases were Black/African American, had fewer years of education, and were current smokers. Compared with controls, cases also were more likely to be in the highest quartile of total energy intake (35 vs. $25 \%$ ), to be overweight (37 vs. $32 \%$ ), and to have been diagnosed with diabetes (14 vs. $10 \%)$.

\section{Vitamin D intake}

In general, risk of pancreatic cancer increased with increased intake of vitamin D from food only in men (Table 2). For total vitamin $\mathrm{D}$ (food and supplement intake), risk increased with increased intake until the highest category of intake ( $\geq 800 \mathrm{IU} /$ day) where risk of pancreatic cancer was less than unity and not different from those with the lowest intake ( $<200$ IU/day). Men with the highest dietary vitamin D intake, without supplements ( $\geq 450 \mathrm{IU} /$ day), had a 2.6 -fold increased risk of pancreatic cancer compared with men with the lowest intake $(<150 \mathrm{IU}$ dietary/day, trend- $p=0.009)$. No statistically significant associations were observed among women. When participants who took vitamin D supplements were included in these analyses, dietary vitamin D intake remained statistically significantly associated with increased risk of pancreatic cancer (for highest vs. lowest intake: Men: $\mathrm{OR}=1.4$, trend- $p=0.02$; Women: $\mathrm{OR}=$ 1.1 , trend- $p=0.09$, data not shown). Dairy foods were the major source of dietary vitamin $\mathrm{D}$ in our study population. However, when models were adjusted for intake of dairy foods, the increased risk of pancreatic cancer associated with dietary vitamin $\mathrm{D}$ intake among men remained unchanged $(\mathrm{ORs}=1.6$ (95\% CI: 0.91-2.7), 1.9 (0.94-3.8), and 2.3 $(0.88-5.8)$ for increasing categories of dietary vitamin D intake, trend- $p=0.05$ ).

Vitamin A and retinol

No associations were observed between pancreatic cancer risk and intake of vitamin $\mathrm{A}$ in men or women (Table 3). 
Table 1 Demographic, health, and lifestyle characteristics of cases and controls in a population-based case-control study of pancreatic cancer, San Francisco Bay Area, California, 1995-1999

\begin{tabular}{|c|c|c|}
\hline Characteristics & $\begin{array}{l}\text { Cases } \\
(n=532)^{\mathrm{a}} \\
n(\%)\end{array}$ & $\begin{array}{l}\text { Controls } \\
(n=1,701) \\
n(\%)\end{array}$ \\
\hline \multicolumn{3}{|l|}{ Age (years) } \\
\hline$<50$ & $46(9)$ & $164(10)$ \\
\hline $50-59$ & $120(22)$ & $438(26)$ \\
\hline $60-69$ & $172(32)$ & $473(28)$ \\
\hline $70-79$ & $158(30)$ & $498(29)$ \\
\hline$\geq 80$ & $36(7)$ & $128(7)$ \\
\hline \multicolumn{3}{|l|}{ Sex } \\
\hline Male & $291(55)$ & $883(52)$ \\
\hline Female & $241(45)$ & $818(48)$ \\
\hline \multicolumn{3}{|l|}{ Race } \\
\hline White & $442(83)$ & $1471(86)$ \\
\hline Black/African American & $46(9)$ & $78(5)$ \\
\hline Asian or Pacific Islander & $35(7)$ & $119(7)$ \\
\hline Others & $9(2)$ & $33(2)$ \\
\hline \multicolumn{3}{|l|}{ Education level } \\
\hline Less than high school & $71(13)$ & $162(10)$ \\
\hline High school & $164(31)$ & $372(22)$ \\
\hline $1-4$ years college & $200(38)$ & $754(44)$ \\
\hline Graduate school & $97(18)$ & $413(24)$ \\
\hline \multicolumn{3}{|l|}{ Diabetes } \\
\hline Yes & $76(14)$ & $161(10)$ \\
\hline \multicolumn{3}{|l|}{ Body mass index $\left(\mathrm{kg} / \mathrm{m}^{2}\right)$} \\
\hline$<25$ & $281(53)$ & $999(59)$ \\
\hline 25 to $<30$ & $197(37)$ & $553(32)$ \\
\hline$\geq 30$ & $54(10)$ & $149(9)$ \\
\hline \multicolumn{3}{|l|}{ Smoking } \\
\hline Non-smoker & $163(31)$ & $652(38)$ \\
\hline Former smoker, quit $>15$ years & $133(25)$ & $508(30)$ \\
\hline Former smoker, quit $1-15$ years & $89(17)$ & $260(15)$ \\
\hline Current smoker \& quit $<1$ year & $131(25)$ & $208(12)$ \\
\hline Pipe/cigar smoker & $16(3)$ & $73(4)$ \\
\hline \multicolumn{3}{|c|}{ Total energy (kcal), quartiles (median) } \\
\hline Q1 $(1,439)$ & $103(20)$ & $425(25)$ \\
\hline Q2 $(1,810)$ & $112(21)$ & $425(25)$ \\
\hline Q3 $(2,015)$ & $124(24)$ & $425(25)$ \\
\hline Q4 $(2,651)$ & $186(35)$ & $426(25)$ \\
\hline
\end{tabular}

${ }^{a}$ Numbers may not add up to the total number of participants because of missing values

An increased OR for the risk of pancreatic cancer was observed among men and women with moderate levels of dietary retinol intake, although individual ORs were not different from unity and the OR was diminished among those with the highest total retinol intake. In general, the pattern of association with retinol was similar to that observed with vitamin $\mathrm{D}$, where CIs for individual ORs were wide and included unity, and the magnitude of the ORs for those with the highest intake was diminished relative to the ORs for low to moderate intake.

\section{Calcium}

ORs for pancreatic cancer risk associated with total calcium intake in men and women were slightly elevated, although individual estimates were not different from unity and the highest category of calcium intake was reduced in women (trend- $p=0.94$ men, and trend- $p=0.02$ women). Dietary calcium intake in food only was associated with an increased risk of pancreatic cancer among men (highest vs. lowest category, $\mathrm{OR}=2.8$, trend- $p=0.008$, Table 3 ). In contrast, no association was observed among women where the pattern of results was similar to the non-linear effects observed for vitamin D (ORs for highest intake were lower than for low to moderate intake).

\section{Associations and interactions among nutrients}

Intake of total vitamin D was moderately correlated with total intake of retinol (Pearson's $r=0.65, p<0.0001$ ) and had moderately low correlations with total intake of vitamin A (Pearson's $r=0.45, p<0.0001$ ) and total intake of calcium (Pearson's $r=0.38, p<0.0001$ ) for men and women combined. In sex-stratified analyses, the correlation results for men and women separately were consistent with those obtained in the combined analysis.

There was evidence in our data that vitamin $\mathrm{D}$, calcium, and retinol were mutual confounders. In models that also included intake of calcium and retinol, pancreatic cancer risk associated with total vitamin D intake among men was unchanged, whereas risk associated with dietary intake only was attenuated, and the trend in risk was no longer statistically significant (highest vs. lowest intake: OR = 1.6 , adjusted trend- $p=0.23$, data not shown). In contrast, the effects of total vitamin D intake in women were greater after additional adjustment for total calcium and total retinol intake and increased with increased total vitamin D intake (highest vs. lowest intake: $\mathrm{OR}=2.4$, adjusted trend- $p=0.05$, data not shown). The association between pancreatic cancer risk and dietary vitamin $\mathrm{D}$ intake in women was unchanged in these expanded models.

No statistically significant interactions between vitamin D intake and retinol were observed in our study population, although some noteworthy variations in pancreatic cancer risk were observed (Table 4). A nearly sixfold increased risk of pancreatic cancer was observed among men with $>450$ IU of dietary vitamin D and low dietary retinol intake (interaction- $p=0.58$, Table 4), and an eightfold increased risk of pancreatic cancer was observed among 
Table 2 Odds ratios (ORs) and 95\% confidence intervals (CIs) for intake of vitamin D and risk of pancreatic cancer in a population-based casecontrol study, San Francisco Bay Area, California, 1995-1999

\begin{tabular}{|c|c|c|c|c|c|c|c|c|c|c|c|c|}
\hline \multirow[t]{2}{*}{ Nutrients } & \multicolumn{6}{|l|}{ Men } & \multicolumn{6}{|l|}{ Women } \\
\hline & $\begin{array}{l}\text { Case } \\
n(\%)\end{array}$ & $\begin{array}{l}\text { Control } \\
n(\%)\end{array}$ & $\mathrm{OR}^{\mathrm{a}, \mathrm{b}}$ & $95 \% \mathrm{CI}$ & $\mathrm{OR}^{\mathrm{a}, \mathrm{c}}$ & $95 \% \mathrm{CI}$ & $\begin{array}{l}\text { Case } \\
n(\%)\end{array}$ & $\begin{array}{l}\text { Control } \\
n(\%)\end{array}$ & $\mathrm{OR}^{\mathrm{a}, \mathrm{b}}$ & $95 \% \mathrm{CI}$ & $\mathrm{OR}^{\mathrm{a}, \mathrm{c}}$ & $95 \% \mathrm{CI}$ \\
\hline \multicolumn{13}{|c|}{ Total vitamin D (diet and vitamin supplements), IU/day } \\
\hline Median, IU/day & 376 & 351 & & & & & 414 & 448 & & & & \\
\hline$<200$ & 49 (17) & $224(25)$ & 1 & & 1 & & 44 (19) & $163(20)$ & 1 & & 1 & \\
\hline 200-399 & $103(36)$ & $255(29)$ & 1.8 & $1.2,2.7$ & 2.0 & $1.4,3.1$ & $70(30)$ & $213(26)$ & 1.2 & $0.76,1.8$ & 1.5 & $0.96,2.4$ \\
\hline $400-599$ & $71(25)$ & $164(19)$ & 1.8 & $1.2,2.8$ & 2.2 & $1.4,3.4$ & 39 (16) & 141 (17) & 1.0 & $0.61,1.7$ & 1.1 & $0.66,1.9$ \\
\hline $600-799$ & 49 (17) & 141 (16) & 1.7 & $1.1,2.7$ & 2.2 & $1.4,3.6$ & 45 (19) & $175(21)$ & 0.96 & $0.59,1.5$ & 1.2 & $0.71,1.9$ \\
\hline$\geq 800$ & $16(6)$ & 99 (11) & 0.81 & $0.43,1.5$ & 0.91 & $0.47,1.7$ & $39(16)$ & $126(15)$ & 1.1 & $0.69,1.9$ & 1.4 & $0.84,2.4$ \\
\hline Trend- $p$ & & & 0.95 & & 0.45 & & & & 0.93 & & 0.64 & \\
\hline \multicolumn{13}{|c|}{ Dietary vitamin D (from food only) ${ }^{\mathrm{d}}$, IU/day } \\
\hline Median, IU/day & 238 & 210 & & & & & 250 & 235 & & & & \\
\hline$<150$ & $29(17)$ & $119(24)$ & 1 & & 1 & & $21(17)$ & $72(18)$ & 1 & & 1 & \\
\hline 150-299 & $91(54)$ & $255(51)$ & 1.4 & $0.87,2.3$ & 1.6 & $0.95,2.6$ & $59(46)$ & $198(49)$ & 1.0 & $0.58,1.8$ & 1.3 & $0.70,2.6$ \\
\hline $300-449$ & $37(22)$ & $93(19)$ & 1.7 & $0.97,3.1$ & 2.0 & $1.1,3.8$ & $38(30)$ & $97(24)$ & 1.3 & $0.70,2.5$ & 2.1 & $1.01,4.2$ \\
\hline$\geq 450$ & $13(8)$ & $29(6)$ & 1.9 & $0.88,4.3$ & 2.6 & $1.1,6.0$ & $9(7)$ & $38(9)$ & 0.82 & $0.33,2.0$ & 0.93 & $0.35,2.5$ \\
\hline Trend- $p$ & & & 0.05 & & 0.009 & & & & 0.87 & & 0.41 & \\
\hline \multicolumn{13}{|c|}{ Vitamin D (from supplements only) ${ }^{\mathrm{e}}$, IU/day } \\
\hline \multicolumn{13}{|l|}{ Median, IU/day } \\
\hline 0 & $170(59)$ & $496(56)$ & 1 & & 1 & & $127(54)$ & $405(50)$ & 1 & & 1 & \\
\hline 0,400 & $12(4)$ & $50(6)$ & 0.75 & $0.38,1.5$ & 0.92 & $0.46,1.9$ & $10(4)$ & $57(7)$ & 0.56 & $0.28,1.1$ & 0.61 & $0.30,1.3$ \\
\hline 400 & $92(32)$ & 279 (32) & 0.97 & $0.72,1.3$ & 1.0 & $0.76,1.4$ & $85(36)$ & 295 (36) & 0.91 & $0.66,1.3$ & 0.97 & $0.70,1.4$ \\
\hline$>400$ & $14(5)$ & $58(7)$ & 0.66 & $0.36,1.2$ & 0.71 & $0.38,1.3$ & $15(6)$ & $61(7)$ & 0.79 & $0.43,1.5$ & 0.82 & $0.44,1.5$ \\
\hline Trend- $p$ & & & 0.38 & & 0.71 & & & & 0.41 & & 0.65 & \\
\hline
\end{tabular}

${ }^{\text {a }}$ Adjusted for energy intake by the residual method

b Adjusted for categories of age and total energy intake

c Additionally adjusted for body mass index, race, education, smoking, history of diabetes, physical activity, and alcohol consumption

${ }^{\mathrm{d}}$ Excludes participants who had any specific nutrient supplement (multivitamin and single supplement)

e Includes participants with multivitamin and single supplement use

women with $>450$ IU of dietary vitamin D and high dietary retinol intake (interaction- $p=0.23$, Table 4 ).

Smoking, physical activity, and vitamin D interactions

Among men, there was no evidence that smoking modified the association between vitamin $\mathrm{D}$ intake and pancreatic cancer risk (interaction- $p=0.40$ for total vitamin D and 0.64 for dietary vitamin $\mathrm{D}$ intake, data not shown). In contrast, among women, there was some weak evidence that risk of pancreatic cancer associated with total vitamin $\mathrm{D}$ intake was higher in non-smokers compared with smokers (interaction- $p=0.12$, data not shown). A similar trend was observed for the intake of dietary vitamin D among women.

In analyses stratified by low and high levels of physical activity, ORs for dietary vitamin D that was associated with pancreatic cancer risk were higher among men who had a low physical activity level and higher in women who had a high physical activity level. However, estimates were imprecise, all confidence intervals included unity and there was no evidence of statistical interaction (all interaction$p>0.15$, data not shown).

\section{Discussion}

In our large population-based case-control study, approximately half of all study participants had adequate total vitamin D intake according to current guidelines. Our results provided support for increased risk of pancreatic cancer with dietary vitamin $\mathrm{D}$ intake in men, although increased risk associated with total vitamin D (vitamin supplements and food) was limited to men with low to 
Table 3 Odds ratios (ORs) and 95\% confidence intervals (CIs) for intake of vitamin A, retinol, and calcium, and risk of pancreatic cancer in a population-based case-control study, San Francisco Bay Area, California, 1995-1999

\begin{tabular}{|c|c|c|c|c|c|c|c|c|c|c|c|c|}
\hline \multirow[t]{2}{*}{ Nutrients } & \multicolumn{6}{|l|}{ Men } & \multicolumn{6}{|l|}{ Women } \\
\hline & $\begin{array}{l}\text { Case } \\
n(\%)\end{array}$ & $\begin{array}{l}\text { Control } \\
n(\%)\end{array}$ & $\mathrm{OR}^{\mathrm{a}, \mathrm{b}}$ & $95 \% \mathrm{CI}$ & $\mathrm{OR}^{\mathrm{a}, \mathrm{c}}$ & $95 \% \mathrm{CI}$ & $\begin{array}{l}\text { Case } \\
n(\%)\end{array}$ & $\begin{array}{l}\text { Control } \\
n(\%)\end{array}$ & $\mathrm{OR}^{\mathrm{a}, \mathrm{b}}$ & $95 \% \mathrm{CI}$ & $\mathrm{OR}^{\mathrm{a}, \mathrm{c}}$ & $95 \% \mathrm{CI}$ \\
\hline \multicolumn{13}{|c|}{ Total vitamin A (diet and vitamin supplements), IU/day } \\
\hline Median, IU/day & 11,945 & 12,729 & & & & & 14,999 & 16,284 & & & & \\
\hline$<5,000$ & $24(8)$ & $62(7)$ & 1.0 & & 1.0 & & $13(6)$ & $37(5)$ & 1.0 & & 1.0 & \\
\hline $5,000-9,999$ & $88(31)$ & $241(27)$ & 0.91 & $0.53,1.6$ & 1.0 & $0.58,1.8$ & $52(22)$ & 159 (19) & 0.81 & $0.39,1.7$ & 1.0 & $0.49,2.2$ \\
\hline $10,000-19,999$ & $132(46)$ & 396 (45) & 0.85 & $0.50,1.4$ & 1.1 & $0.61,1.9$ & $110(46)$ & $339(41)$ & 0.80 & $0.40,1.6$ & 1.1 & $0.52,2.3$ \\
\hline$\geq 20,000$ & $44(15)$ & $184(21)$ & 0.62 & $0.34,1.1$ & 0.78 & $0.42,1.5$ & $62(26)$ & $283(35)$ & 0.54 & $0.26,1.1$ & 0.78 & $0.36,1.7$ \\
\hline Trend- $p$ & & & 0.05 & & 0.22 & & & & 0.01 & & 0.12 & \\
\hline \multicolumn{13}{|c|}{ Dietary vitamin A (from food only) ${ }^{\mathrm{d}}$, IU/day } \\
\hline Median, IU/day & 9,081 & 9,271 & & & & & 10,060 & 10,950 & & & & \\
\hline$<5,000$ & $25(15)$ & $59(13)$ & 1.0 & & 1.0 & & $10(8)$ & $38(10)$ & 1.0 & & 1.0 & \\
\hline $5,000-9,999$ & $74(44)$ & $198(43)$ & 0.88 & $0.50,1.5$ & 0.91 & $0.50,1.6$ & $51(41)$ & $130(34)$ & 1.5 & $0.67,3.3$ & 1.9 & $0.81,4.6$ \\
\hline $10,000-19,999$ & $58(35)$ & $170(36)$ & 0.82 & $0.46,1.5$ & 0.91 & $0.49,1.7$ & $49(40)$ & 149 (39) & 1.2 & $0.56,2.8$ & 1.7 & $0.68,4.1$ \\
\hline$\geq 20,000$ & $10(6)$ & $39(8)$ & 0.63 & $0.26,1.5$ & 0.68 & $0.27,1.7$ & $14(11)$ & $65(17)$ & 0.90 & $0.35,2.3$ & 1.2 & $0.44,3.5$ \\
\hline Trend- $p$ & & & 0.30 & & 0.48 & & & & 0.27 & & 0.56 & \\
\hline \multicolumn{13}{|c|}{ Total retinol (diet and vitamin supplements), IU/day } \\
\hline Median, IU/day & 2,994 & 2,980 & & & & & 3,464 & 3,284 & & & & \\
\hline$<2,000$ & 107 (37) & $368(42)$ & 1.0 & & 1.0 & & 88 (37) & 303 (37) & 1.0 & & 1.0 & \\
\hline $2,000-3,999$ & $70(24)$ & 172 (19) & 1.4 & $1.0,2.1$ & 1.5 & $1.0,2.1$ & $57(24)$ & 157 (19) & 1.2 & $0.83,1.8$ & 1.3 & $0.85,1.9$ \\
\hline $4,000-7,999$ & $87(30)$ & 244 (28) & 1.3 & $0.91,1.8$ & 1.4 & $0.97,1.9$ & $65(28)$ & $244(30)$ & 0.92 & $0.63,1.3$ & 0.94 & $0.64,1.4$ \\
\hline$\geq 8,000$ & $24(8)$ & $99(11)$ & 0.92 & $0.55,1.5$ & 0.93 & $0.55,1.6$ & $27(11)$ & $114(14)$ & 0.82 & $0.50,1.3$ & 0.92 & $0.55,1.5$ \\
\hline Trend- $p$ & & & 0.97 & & 0.78 & & & & 0.29 & & 0.54 & \\
\hline \multicolumn{13}{|c|}{ Dietary retinol (from food only) ${ }^{\mathrm{d}}$, IU/day } \\
\hline Median, IU/day & 1,493 & 1,274 & & & & & 1,417 & 1,418 & & & & \\
\hline$<2,000$ & $115(67)$ & $356(73)$ & 1.0 & & 1.0 & & $83(63)$ & $291(72)$ & 1.0 & & 1.0 & \\
\hline $2,000-3,999$ & $42(25)$ & $100(20)$ & 1.5 & $0.96,2.3$ & 1.6 & $1.0,2.6$ & $35(27)$ & $87(21)$ & 1.4 & $0.90,2.3$ & 1.3 & $0.78,2.2$ \\
\hline$\geq 4,000$ & $14(8)$ & $34(7)$ & 1.6 & $0.79,3.1$ & 1.6 & $0.80,3.3$ & $13(10)$ & $29(7)$ & 1.7 & $0.81,3.4$ & 1.6 & $0.73,3.4$ \\
\hline Trend- $p$ & & & 0.06 & & 0.04 & & & & 0.07 & & 0.17 & \\
\hline \multicolumn{13}{|c|}{ Total calcium (diet and vitamin supplements), mg/day } \\
\hline Median, mg/day & 726 & 714 & & & & & 887 & 1,051 & & & & \\
\hline$<500$ & $38(13)$ & $143(16)$ & 1.0 & & 1.0 & & $24(10)$ & $75(9)$ & 1.0 & & 1.0 & \\
\hline $500-799$ & $137(48)$ & $384(43)$ & 1.3 & $0.85,2.0$ & 1.4 & $0.88,2.1$ & $75(32)$ & $205(25)$ & 1.1 & $0.66,1.9$ & 1.3 & $0.75,2.3$ \\
\hline $800-1,199$ & $81(28)$ & $245(28)$ & 1.1 & $0.69,1.7$ & 1.2 & $0.73,1.9$ & $69(29)$ & $194(24)$ & 1.1 & $0.62,1.8$ & 1.5 & $0.82,2.6$ \\
\hline$\geq 1,200$ & $32(11)$ & 111 & 1.0 & $0.58,1.8$ & 1.2 & $0.68,2.1$ & 69 (29) & $344(42)$ & 0.61 & $0.36,1.0$ & 0.81 & $0.45,1.4$ \\
\hline Trend- $p$ & & & 0.5 & & 0.94 & & & & 0.001 & & 0.02 & \\
\hline \multicolumn{13}{|c|}{ Dietary calcium (from food only) ${ }^{\mathrm{d}}, \mathrm{mg} /$ day } \\
\hline Median, mg/day & 665 & 634 & & & & & 711 & 716 & & & & \\
\hline$<500$ & $38(17)$ & $143(23)$ & 1.0 & & 1.0 & & $22(17)$ & $62(18)$ & 1.0 & & 1.0 & \\
\hline $500-799$ & $123(54)$ & $340(54)$ & 1.3 & $0.88,2.0$ & 1.4 & $0.88,2.2$ & $64(46)$ & 168 (47) & 1.1 & $0.61,1.9$ & 1.3 & $0.68,2.4$ \\
\hline $800-1,199$ & $52(23)$ & $125(20)$ & 1.5 & $0.90,2.4$ & 1.7 & $0.99,2.8$ & $42(30)$ & $86(24)$ & 1.3 & $0.71,2.5$ & 1.8 & $0.91,3.7$ \\
\hline$\geq 1,200$ & $14(6)$ & $22(3)$ & 2.5 & $1.2,5.6$ & 2.8 & $1.2,6.4$ & $10(7)$ & $39(11)$ & 0.76 & $0.32,1.8$ & 0.70 & $0.27,1.8$ \\
\hline Trend- $p$ & & & 0.02 & & 0.008 & & & & 0.86 & & 0.88 & \\
\hline
\end{tabular}

a Adjusted for energy intake by the residual method

b Adjusted for categories of age and total energy intake

c Additionally adjusted for body mass index, race, education, smoking, history of diabetes, physical activity, and alcohol consumption

${ }^{\mathrm{d}}$ Excludes participants who had any specific nutrient supplement (multivitamin and single supplement) 
Table 4 Odds ratios (ORs) and 95\% confidence intervals (CIs) for risk of pancreatic cancer with the examination of interaction effects between vitamin D intake and intake of retinol in a population-based case-control study, San Francisco Bay Area, California, 1995-1999

\begin{tabular}{|c|c|c|c|c|c|c|c|c|c|}
\hline \multicolumn{5}{|c|}{ Total vitamin D (diet and vitamin supplements), IU/day } & \multicolumn{5}{|c|}{ Dietary vitamin D (from food only) ${ }^{\mathrm{b}}, \mathrm{IU} /$ day } \\
\hline \multirow{2}{*}{$\begin{array}{l}\text { Categories } \\
\text { Retinol intak }\end{array}$} & \multicolumn{2}{|c|}{ Men } & \multicolumn{2}{|c|}{ Women } & \multirow[t]{2}{*}{ Categories } & \multicolumn{2}{|c|}{ Men } & \multicolumn{2}{|c|}{ Women } \\
\hline & $\mathrm{OR}^{\mathrm{a}}$ & $95 \% \mathrm{CI}$ & $\mathrm{OR}^{\mathrm{a}}$ & $95 \% \mathrm{CI}$ & & $\mathrm{OR}^{\mathrm{a}}$ & $95 \% \mathrm{CI}$ & $\mathrm{OR}^{\mathrm{a}}$ & $95 \% \mathrm{CI}$ \\
\hline \multicolumn{5}{|c|}{ Low total retinol intake } & \multicolumn{5}{|c|}{ Low dietary retinol intake } \\
\hline & \multicolumn{2}{|c|}{$<2,980$ IU/day } & \multicolumn{2}{|c|}{$<3,284$ IU/day } & & \multicolumn{2}{|c|}{$<1,274$ IU/day } & \multicolumn{2}{|c|}{$<1,418$ IU/day } \\
\hline$<200$ & 1 & & 1 & & $<150$ & 1 & & 1 & \\
\hline $200-399$ & 2.1 & $1.3,3.3$ & 1.4 & $0.84,2.5$ & $150-299$ & 1.3 & $0.66,2.6$ & 1.0 & $0.46,2.2$ \\
\hline $400-599$ & 2.4 & $1.2,4.8$ & 0.87 & $0.41,1.9$ & $300-449$ & 1.5 & $0.46,4.8$ & 1.1 & $0.40,3.3$ \\
\hline $600-799$ & NA & & 1.1 & $0.34,3.2$ & $\geq 450$ & 5.6 & $1.2,26.4$ & 0.2 & $0.02,2.3$ \\
\hline$\geq 800$ & NA & & 2.0 & $0.41,9.9$ & & & & & \\
\hline
\end{tabular}

Retinol intake

High total retinol intake

\begin{tabular}{|c|c|c|c|c|c|c|c|c|c|}
\hline & \multicolumn{2}{|c|}{$\geq 2,980$ IU/day } & \multicolumn{3}{|c|}{$\geq 3,284 \mathrm{IU} /$ day } & \multicolumn{2}{|c|}{$\geq 1,274$ IU/day } & \multicolumn{2}{|c|}{$\geq 1,418$ IU/day } \\
\hline$<200$ & 1 & & 1 & & $<150$ & 1 & & 1 & \\
\hline $200-399$ & 1.5 & $0.49,4.6$ & 2.4 & $0.61,9.5$ & $150-299$ & 1.6 & $0.61,4.2$ & 9.6 & $1.3,70.6$ \\
\hline $400-599$ & 1.8 & $0.63,5.4$ & 1.6 & $0.43,5.9$ & $300-449$ & 1.9 & $0.68,5.4$ & 21.6 & $2.7,174.6$ \\
\hline $600-799$ & 2 & $0.70,5.9$ & 1.5 & $0.41,5.1$ & $\geq 450$ & 1.9 & $0.53,6.6$ & 8.0 & $0.91,70.0$ \\
\hline$\geq 800$ & 0.75 & $0.24,2.4$ & 1.9 & $0.52,6.7$ & & & & & \\
\hline Interaction- $p$ & $0.19^{\mathrm{c}}$ & & 0.66 & & & 0.58 & & 0.23 & \\
\hline
\end{tabular}

${ }^{\text {a }}$ Adjusted for energy intake by the residual method, categories of age, total energy intake, body mass index, race, education, smoking, history of diabetes, physical activity, and alcohol consumption

${ }^{\mathrm{b}}$ Excludes participants who had any specific nutrient supplement (multivitamin and single supplement)

${ }^{c}$ Due to small numbers of participants with total vitamin D intake $\geq 600 \mathrm{IU} / \mathrm{day}$, the two upper categories were collapsed for the test of statistical interaction between intake of total vitamin $\mathrm{D}$ intake and intake of total retinol

moderate levels of intake and was diminished in the highest category of intake. The pattern of association between calcium intake (total and dietary) and pancreatic cancer risk was similar to that observed with vitamin $\mathrm{D}$ and again was observed in men and not in women. In both men and women, the association with calcium was confounded by vitamin D intake. Vitamin A intake was not associated with pancreatic cancer risk in men or women. Increased risks were suggested for men and women with increased dietary retinol intake, although results could have been due to chance.

The Institute of Medicine's (IOM) Food and Nutrition Board currently recommends Dietary Reference Intake (DRI) of total vitamin D at $400 \mathrm{IU} /$ day for most adults and 600 IU/day for those $>70$ years of age. In our study, median total vitamin D intake was adequate for those under the age of 70 years (423 IU/day for men, 487 IU/day for women), but not for those who were $>70$ years of age (453 IU/day for men, $497 \mathrm{IU} /$ day for women). We observed that men with total vitamin D intake above the DRI had lower risks than those in the lowest category of intake. Recommendations recently have been published advocating that the DRI be doubled [31] or be raised to 2,000 IU/day [32]. An expert panel of the IOM currently is reviewing the official vitamin $\mathrm{D}$ recommendations that last were updated in 1997. Final recommendations are expected in 2010 [33].

Few population-based studies have investigated the association between vitamin D and its analogs with pancreatic cancer risk, and their results have been inconsistent, and overall, inconclusive. Similar to our findings, the Alpha-Tocopherol, Beta-Carotene Cancer Prevention Study (ATBC) among male Finnish smokers aged 50-69 years reported a threefold significantly increased risk of pancreatic cancer among those with the highest serum concentrations of the vitamin D metabolite 25(OH)D [15] ( $>65.5$ vs. $<32.0 \mathrm{nmol} / \mathrm{l})$. However, in the earlier analyses, dietaryrelated vitamin D levels were not associated with risk [14]. The authors importantly noted that for the majority of the Finnish study participants, vitamin D levels indicated vitamin D deficiency (median dietary and total intake $4.9 \mathrm{mcg}$ (196 IU/day) for cases and controls) and therefore their results may be applicable to a vitamin D deficient population only [14]. The largest to date pooled analysis of 
eight cohort studies reported a statistically significant twofold increase in the risk of pancreatic cancer associated with a high $25(\mathrm{OH}) \mathrm{D}$ serum concentration ( $\geq 100$ vs. 50-75 nmol/l) [17].

These results contrast with those from a pooled analysis of two cohort studies [10] and with a recent case-control study nested within the Prostate, Lung, Colorectal, and Ovarian (PLCO) screening trial [16]. Although the results from the cohort studies showed a decreased risk with increased vitamin D intake, similar to our results, the effect appeared to be restricted to men [10]. The results from the PLCO study are inconsistent with our and other's results. Investigators reported no association between serum $25(\mathrm{OH}) \mathrm{D}$ and pancreatic cancer in models adjusted for time of year of blood draw (to account for a seasonal UVB effect on vitamin D metabolite levels) [16]. The discrepant results emphasize the complexity of a relationship between vitamin $\mathrm{D}$ and pancreatic cancer risk that includes the multiple methods that have been used by studies to determine a valid and informative measure of vitamin D status.

Vitamin D is a fat-soluble vitamin, and its concentration depends upon supplements, dietary consumption of vitamin D-rich foods and on endogenous production when ultraviolet rays from sunlight strike the skin and trigger vitamin D synthesis [34]. Studies based on reported dietary vitamin D intake have a limited ability to account for solar-associated skin production of vitamin D. This is further complicated by known differences in individual ability to synthesize vitamin D from the sun, including phenotypic characteristics of the skin, i.e., melanin, age, geographic longitude and latitude, seasonal variation, and personal sun protection. Thus, accurate measurement of vitamin D depends upon measuring concentrations of its metabolites. One metabolite, 25-hydroxyvitamin D [35], is produced by the liver and is affected by recent vitamin $\mathrm{D}$ intake. In addition, the integral effects of vitamin $\mathrm{A}$ and retinol levels (antagonists to vitamin D), calcium intake and absorption (regulated by vitamin D and at high levels a regulator of the production of the active form of vitamin D) [18], and genetic variation in the expression of vitamin $\mathrm{D}$ receptors need to be considered as they may confound or modify the association between vitamin D levels and pancreatic cancer risk. Our results combined with those of other published studies emphasize a need to identify measures of dietary and non-dietary effects on vitamin $\mathrm{D}$ status to gain a better understanding of whether vitamin D may alter risk of pancreatic cancer.

Intake of vitamin D supplements, retinol, and calcium level of physical activity or smoking did not confound or modify the association between dietary vitamin D intake and risk of pancreatic cancer. Further, the increased risks observed among men did not differ by high or low level of dietary retinol, or by level of physical activity, although
ORs were slightly lower for higher physical activity levels (2-3 times/week). In contrast, there was no clear pattern of risks among women. The difference in risks between men and women may be due to: differential sun exposure; women's higher percentage of body fat beyond that measured by body mass index [36]; or differences in dietary and supplement-use patterns.

The strengths and weaknesses of case-control study design and methods used to ascertain dietary intake should be considered when interpreting the results from our study. Information bias due to differential reporting of diet by cases and controls is possible, although dietary risk factors for pancreatic cancer are not firmly established nor widely known in the community [5]. Therefore, it is less likely that cases recalled their diet differently from controls, and our response rates for cases and controls were similar. Overall survival of our cases was not associated with vitamin D intake among men and women (trend- $p=0.68$ men, and trend- $p=0.89$ women, respectively), and the median time from diagnosis to interview was less than 2 months. Thus, although it is unlikely that our results were affected by selection bias related to the rapid and high mortality among pancreatic cancer cases, it is possible that our results pertain to 'healthier' pancreatic cancer patients.

Vitamin D levels also are affected by endogenous vitamin D synthesis in the skin related to relatively short exposure to ultraviolet rays from sunlight $[6,10]$. Due to rapid progression of pancreatic cancer, most cases are unlikely to have experienced conditions or symptoms that would greatly limit their activities for an extended period of time before their pancreatic cancer diagnosis. Thus, differentially lower sun exposure among cases is unlikely, but the data regarding sun exposure were not available for these analyses. It is more likely that age-related factors would impact outdoor activity and sun-related vitamin D production and our matching by age groups would help to adjust for age-related effects.

The strengths of our study are many and include the population-based design providing for comparability of cases and controls on many measured and unmeasured confounding variables. Case-control study design allowed for greater power to test study hypotheses by including a large number of population-based incident pancreatic cancer cases identified from a cancer registry. The large sample size provided adequate power to explore statistical associations of interest and to explore confounding and effect modification. Adequacy of the FFQ instrument has been validated in multiple studies, both by re-testing study participants using the same instrument and by comparing nutrient intake from a food-frequency questionnaire with a 7-day recall diary [20, 21].

Our results suggesting that lower intake of dietary vitamin D and dietary calcium may be associated with risk 
of pancreatic cancer in men require confirmation in independent studies with careful assessment in the highest categories of intake where risk was diminished. Continued investigation in studies designed to assess multiple exposures, and factors that affect vitamin D levels are warranted to elucidate the non-linear associations with vitamin $\mathrm{D}$ and calcium intake that were observed in our study population. Few modifiable risk factors have been identified for pancreatic cancer. Data that can be used to determine an ideal level of vitamin D intake and clarify the complex role of vitamin $\mathrm{D}$ and calcium intake in pancreatic cancer risk may be translated to prevention and intervention strategies for this highly fatal cancer.

Acknowledgments This work was supported in part by National Cancer Institute grants (CA59706, CA108370, CA109767, and CA89726 to E.A.H. as P.I.) and by the Rombauer Pancreatic Cancer Research Fund. The collection of cancer incidence data for the UCSF study was supported by the California Department of Public Health as part of the statewide cancer reporting program; the National Cancer Institute's Surveillance, Epidemiology and End Results Program under contract N01-PC-35136 awarded to the Northern California Cancer Center; and the Centers for Disease Control and Prevention's National Program of Cancer Registries, under agreement \#U55/ CCR921930-02 awarded to the Public Health Institute.

Open Access This article is distributed under the terms of the Creative Commons Attribution Noncommercial License which permits any noncommercial use, distribution, and reproduction in any medium, provided the original author(s) and source are credited.

\section{References}

1. Jemal A, Siegel R, Ward E, Hao Y, Xu J, Thun MJ (2009) Cancer statistics. CA Cancer J Clin 59(4):225-249

2. Curado MP, Edwards B, Shin HR, Storm H, Ferlay J, Heanue M, et al. (2007) Cancer incidence in five Continents: vol. IX. IARC Scientific Publications No. 160, Lyon

3. Cameron JL (2001) Pancreatic Cancer, 1st edn. B. C. Decker Incorporated, London

4. Raimondi S, Maisonneuve P, Lowenfels AB (2009) Epidemiology of pancreatic cancer: an overview. Nat Rev Gastroenterol Hepatol 6(12):699-708

5. Howe GR, Burch JD (1996) Nutrition and pancreatic cancer. Cancer Causes Control 7(1):69-82

6. Stolzenberg-Solomon RZ (2009) Vitamin D and pancreatic cancer. Ann Epidemiol 19(2):89-95

7. Palomer X, Gonzalez-Clemente JM, Blanco-Vaca F, Mauricio D (2008) Role of vitamin D in the pathogenesis of type 2 diabetes mellitus. Diabetes Obes Metab 10(3):185-197

8. Alfonso B, Liao E, Busta A, Poretsky L (2009) Vitamin D in diabetes mellitus-a new field of knowledge poised for D-velopment. Diabetes Metab Res Rev 25(5):417-419

9. Grant WB (2002) An estimate of premature cancer mortality in the U.S. due to inadequate doses of solar ultraviolet-B radiation. Cancer 94(6): 1867-1875

10. Skinner HG, Michaud DS, Giovannucci E, Willett WC, Colditz GA, Fuchs CS (2006) Vitamin D intake and the risk for pancreatic cancer in two cohort studies. Cancer Epidemiol Biomarkers Prev 15(9):1688-1695
11. Boscoe FP, Schymura MJ (2006) Solar ultraviolet-B exposure and cancer incidence and mortality in the United States, 1993-2002. BMC Cancer 6:264

12. Guyton KZ, Kensler TW, Posner GH (2003) Vitamin D and vitamin $\mathrm{D}$ analogs as cancer chemopreventive agents. Nutr Rev 61(7):227-238

13. Zugmaier G, Jager R, Grage B, Gottardis MM, Havemann K, Knabbe C (1996) Growth-inhibitory effects of vitamin D analogues and retinoids on human pancreatic cancer cells. Br J Cancer 73(11):1341-1346

14. Stolzenberg-Solomon RZ, Pietinen P, Taylor PR, Virtamo J, Albanes D (2002) Prospective study of diet and pancreatic cancer in male smokers. Am J Epidemiol 155(9):783-792

15. Stolzenberg-Solomon RZ, Vieth R, Azad A, Pietinen P, Taylor PR, Virtamo J et al (2006) A prospective nested case-control study of vitamin D status and pancreatic cancer risk in male smokers. Cancer Res 66(20):10213-10219

16. Stolzenberg-Solomon RZ, Hayes RB, Horst RL, Anderson KE, Hollis BW, Silverman DT (2009) Serum vitamin D and risk of pancreatic cancer in the prostate, lung, colorectal, and ovarian screening trial. Cancer Res 69(4):1439-1447

17. Stolzenberg-Solomon RZ, Jacobs EJ, Arslan AA, Qi D, Patel AV, Helzlsouer KJ et al (2010) Circulating 25-hydroxyvitamin D and risk of pancreatic cancer: cohort consortium vitamin d pooling project of rarer cancers. Am J Epidemiol 172(1):81-93

18. Rohde CM, DeLuca HF (2005) All-trans retinoic acid antagonizes the action of calciferol and its active metabolite, 1, 25dihydroxycholecalciferol, in rats. J Nutr 135(7):1647-1652

19. Heaney RP (2008) Vitamin D and calcium interactions: functional outcomes. Am J Clin Nutr 88(2):541S-544S

20. Chan JM, Wang F, Holly EA (2005) Vegetable and fruit intake and pancreatic cancer in a population-based case-control study in the San Francisco Bay area. Cancer Epidemiol Biomarkers Prev 14(9):2093-2097

21. Chan JM, Wang F, Holly EA (2007) Pancreatic cancer, animal protein and dietary fat in a population-based study, San Francisco Bay area, California. Cancer Causes Control 18(10):1153-1167

22. Holly EA, Eberle CA, Bracci PM (2003) Prior history of allergies and pancreatic cancer in the San Francisco Bay area. Am J Epidemiol 158(5):432-441

23. Colditz GA, Willett WC, Stampfer MJ, Sampson L, Rosner B, Hennekens CH et al (1987) The influence of age, relative weight, smoking, and alcohol intake on the reproducibility of a dietary questionnaire. Int J Epidemiol 16(3):392-398

24. Feskanich D, Rimm EB, Giovannucci EL, Colditz GA, Stampfer MJ, Litin LB et al (1993) Reproducibility and validity of food intake measurements from a semiquantitative food frequency questionnaire. J Am Diet Assoc 93(7):790-796

25. Rimm EB, Giovannucci EL, Stampfer MJ, Colditz GA, Litin LB, Willett WC (1992) Reproducibility and validity of an expanded selfadministered semiquantitative food frequency questionnaire among male health professionals. Am J Epidemiol 135(10):1114-1126 discussion 27-36

26. Willett WC, Reynolds RD, Cottrell-Hoehner S, Sampson L, Browne ML (1987) Validation of a semi-quantitative food frequency questionnaire: comparison with a 1-year diet record. J Am Diet Assoc 87(1):43-47

27. Subar AF, Thompson FE, Kipnis V, Midthune D, Hurwitz P, McNutt $S$ et al (2001) Comparative validation of the Block, Willett, and National Cancer Institute food frequency questionnaires : the eating at America's table study. Am J Epidemiol 154(12):1089-1099

28. Holmes MD, Powell IJ, Campos H, Stampfer MJ, Giovannucci EL, Willett WC (2007) Validation of a food frequency questionnaire measurement of selected nutrients using biological markers in African-American men. Eur J Clin Nutr 61(11):1328-1336 
29. United States Department of Agriculture (1993) Composition of foods - raw, processed, and prepared, 1963-1992. Agricultural handbook no. 8. Department of Agriculture, Government Printing Office, Washington, DC

30. Willett W, Stampfer MJ (1986) Total energy intake: implications for epidemiologic analyses. Am J Epidemiol 124(1):17-27

31. Willett WC, Stampfer MJ (2001) Clinical practice. What vitamins should I be taking, doctor? N Engl J Med 345(25): 1819-1824

32. Giovannucci E (2009) Expanding roles of vitamin D. J Clin Endocrinol Metab 94(2):418-420

33. Yetley EA, Brule D, Cheney MC, Davis CD, Esslinger KA, Fischer PW et al (2009) Dietary reference intakes for vitamin D: justification for a review of the 1997 values. Am J Clin Nutr 89(3):719-727

34. DeLuca HF, Zierold C (1998) Mechanisms and functions of vitamin D. Nutr Rev 56(2 Pt 2):S4-S10, discussion S54-S75

35. Ingraham BA, Bragdon B, Nohe A (2008) Molecular basis of the potential of vitamin D to prevent cancer. Curr Med Res Opin 24(1):139-149

36. McCullough ML, Weinstein SJ, Freedman DM, Helzlsouer K, Flanders WD, Koenig K et al (2010) Correlates of circulating 25hydroxyvitamin $\mathrm{D}$ : cohort consortium vitamin $\mathrm{D}$ pooling project of rarer cancers. Am J Epidemiol 172(1):21-35 